\title{
IDENTIFICATION OF THE MOST IMPORTANT FACTORS IN THE COMPACTION PROCESS
}

\author{
Antonio AMADORE, Gaetano BOSURGI, Orazio PELLEGRINO \\ Department of Civil Engineering, University of Messina, Contrada di Dio, \\ Villaggio S. Agata, 98166 Messina, Italy \\ Received 07 Nov 2011; accepted 02 Feb 2012
}

\begin{abstract}
The compaction of a hot mix asphalt depends on a number of important factors whose control, during the execution of the pavement, is complex; however it is essential to achieve the results envisaged in the design with the least possible cost. Therefore, the evaluation of the effect of these variables on the material density is important as well as their quantification in real time. This research, starting from a survey of some environmental variables, together with the hot mix asphalt density using an electrical impedance device, through the application of a neuro-fuzzy technique, proposes a procedure to classify the most important features. These results can be rapidly deduced during the paving operations; calibrations required to correct the compaction can be applied on site without waiting further time necessary for the extraction of the cores and the subsequent laboratory analysis. In this way it is possible to identify with a better precision the aspects of the environmental context requiring more attention. In addition, the model permits the inclusion of new input variables and additional data that can be recorded in following phases.
\end{abstract}

Keywords: compaction, hot mix asphalt, density, neuro fuzzy, electrical density gauge.

Reference to this paper should be made as follows: Amadore, A.; Bosurgi, G.; Pellegrino, O. 2013. Identification of the most important factors in the compaction process, Journal of Civil Engineering and Management 19(Supplement 1): S116-S124. http://dx.doi.org/10.3846/13923730.2013.801893

\section{Introduction}

Compaction is the process by which the density of a hot mix asphalt is increased by using rollers to orient the aggregate particles in a better way (Scherocman, Martenson 1984; Scherocman 1984; Geller 1984; Brown 1984; Bell et al. 1984; Roberts et al. 1996). In the construction of a road there are frequent cases where, due to inadequate compaction of the material, the pavement does not reach the constructional and functional standards required by the design. As a matter of fact, a good density of the material implies a better quality of the road in terms of strength to plastic deformation, fatigue and capability to withstand traffic loads, water, aging and cracking due to low temperatures (Hughes 1989). In the last years a greater awareness of the true complexity of the subject has been reached thanks to technological advances, a more detailed knowledge of materials, new laboratory tests faithful to the real performance on the road and analytical modelling increasingly precise and sophisticated (Kavussi, Hashemian 2011).

\section{Problems}

As it is well known, the success of compaction depends critically on the design phase, where appropriate laboratory tests help to address the executive phase. Over the last few years some procedures have been improved so that the results of the laboratory can be achieved on site with a good approximation (Khan et al. 1998; Dubois et al. 2010). There are a lot of variables that influence the phenomenon and they are generally related to the environment, to the hot mix asphalt and to the construction operations. For this reason, researchers considered with great interest automated procedures that would allow the management of operations on site in an optimal way and in accordance with the economic constraints (Krishnamurthy et al. 1998).

Some priority issues were studied in depth as compaction temperature, technological progress of the rollers, care of vulnerable construction elements (joints, proximity to bridges and walls) and contractual obligations to guarantee the quality of work (TRB 2006). In this regard, the temperature of the material is one of the most analysed feature. In fact, when it is low, the asphalt binder becomes more viscous and there is some difficulty to decrease air voids for a given compactive effort. With temperature decreasing below a certain threshold (cessation temperature) and depending on other mix properties, it is almost impossible to reduce air voids regardless of the applied compactive effort (Hughes 1989). After this point, rollers can only make better the surface smoothness without further compaction. At this purpose, knowledge of the initial 
temperature and cool-down rate allow to estimate the temperature of the material at any time since this activity must be finished before cessation temperature is reached. Knowledge of this parameter involves the geometry of the paving, the roller choice and other characteristics already reported in Table 1 (Roberts et al. 1996).

Table 1. Some factors affecting compaction

\begin{tabular}{l|l|l}
\hline $\begin{array}{c}\text { Environmental } \\
\text { factors }\end{array}$ & \multicolumn{1}{|c}{$\begin{array}{c}\text { Mix properties } \\
\text { factors }\end{array}$} & \multicolumn{1}{c}{$\begin{array}{c}\text { Construction } \\
\text { factors }\end{array}$} \\
\hline $\begin{array}{l}\text { Ground } \\
\text { temperature }\end{array}$ & Aggregate shape & Rollers type \\
\hline Air temperature & Aggregate gradation & Rollers speed \\
\hline Wind speed & $\begin{array}{l}\text { Aggregate fractured } \\
\text { faces }\end{array}$ & Number of passes \\
\hline Solar flux & Volume & Lift thickness \\
\hline & $\begin{array}{l}\text { Asphalt chemical } \\
\text { properties }\end{array}$ & $\begin{array}{l}\text { HMA production } \\
\text { temperature }\end{array}$ \\
\hline & $\begin{array}{l}\text { Asphalt physical } \\
\text { properties }\end{array}$ & Haul distance \\
\hline & Asphalt amount & Haul time \\
\hline & & $\begin{array}{l}\text { Foundation } \\
\text { support }\end{array}$ \\
\hline
\end{tabular}

Jordan and Thomas (1976) point out some factors affecting this cool-down rate as material density, pavement layer thermal conductivity, specific heat, convection coefficient, incident solar radiation and coefficients of emission and absorption of solar radiation for the pavement surface.

Some characteristics of the aggregates influence also the capability of the asphalt mixture to be rearranged under roller action, as surface texture, particle shape and the number of fractured faces. Of course, compaction energy should also be commensurate with the content of bitumen as if a low energy level cannot effectively thicken the material, an excess in the opposite direction may cause the shoving under roller loads (Airey et al. 2008).

For this reason several factors, associated with the field operations, complicate the question further and must be calibrated from a work to another one. The most important are:

- Static and dynamic characteristics of the roller (Hildebrand et al. 2008);

- Geometrical characteristics of the roller;

- Roller speed. During the passage of the roller there is a compression under the contact area and a shear stress between the compressed area and adjacent uncompressed areas. At lower speeds the roller remains in contact with hot mix asphalt for a long time. The consequence is a bigger compression per roller pass and a higher shear stress, due to the difference between compressed and uncompressed zone;

- Number of roller passes over a given area. A roller pass is one complete trip over the area in question by the entire roller. This means that if the roller has two steel drums, both drums must travel over the area in question to make "one pass".

\section{Procedures}

The theme of compaction has always been treated through two parallel paths: a theoretical approach, based on models (Koneru et al. 2008) and an experimental feedback, necessary to validate the correctness of the first (Commuri, Zaman 2008). There is a need, therefore, to know the density value with good reliability in a brief time in order to be able to make adjustments during the execution. Traditional laboratory tests performed on core samples taken during rolling are certainly reliable, but they are not characterized by the rapidity needed to maintain the ratio performance-costs optimal (Praticò, Moro 2011). New general-purpose equipment have been constructed, with the aim to survey large amounts of data and to permit a more accurate control on site (Leng et al. 2011). This is extremely delicate, because if done improperly, it could adversely impact the following analysis.

Tools to resolve these issues can reasonably be based on soft computing techniques such as fuzzy logic, neural networks and genetic algorithms (Pellegrino 2011, 2012). Indeed, the use of probabilistic analysis is too complex to define and resolve because of the many variables that barely lead to a resolution of the initial problem (Altunok et al. 2006; Sadeghi et al. 2010). The soft computing approach is certainly not always preferable to other methods. It produces more realistic results when the number of variables involved is considerable (Chiu 1996) and, especially, when their non linear dependence would make other techniques not applicable (Dubois, Prade 1998; Chao 2007; Dagdeviren et al. 2008; Grassi et al. 2009; Reuter, Moller 2010; Bosurgi et al. 2011). As a matter of fact, the treatment of uncertainties in probabilistic terms is correct when the system consists of components whose reliability in a given period of time is measured and verified and whose variability is sufficiently small (Papoulis, Pillai 2002). Unfortunately, when the phenomenon is so complex, the sample is strongly inhomogeneous and presents high variability such as to produce very inaccurate final results (Dorsey, Coovert 2003).

In recent years some techniques regarding pattern recognition have been developed for the treatment of large quantities of data recorded by digital instruments (Bosurgi et al. 2010). These techniques have been applied to sort, classify or extract data useful for understanding the phenomenon investigated. The main advantages regard the comprehension of the phenomenon, beside of concerning the elimination of irrelevant dimensions or the reduction of data acquisition cost. At the beginning, these techniques were developed because the time calculating of the early computers was very restrictive and it was necessary to minimize the dimensionality of pattern representation. Later, it became clear that reducing the dimensionality of the data base there was a better performance of the model (Duda et al. 2001; McLachlan 2004; Ripley 2005; Theodoridis, Koutroumbas 2006; Webb 2002). 


\section{The aim of the present research}

In the present work, the authors want to propose a method that, starting from the acquisition of an opportune survey regarding some important factors, allow the recognition of the critical aspects in the compaction phenomenon. In this way their control at different stages of execution is possible. The first step involves the predisposition of a database containing variables related essentially to the roller type and environmental conditions. The complex links that are generated between them have directed the study towards the application of a neuro-fuzzy technique that has allowed identification of the factors that influence material density more. This knowledge should permit to adjust some details in order to have the best performance of compaction with the minor cost of time and money. The procedure is particularly economical and versatile so that it could constitute a new tool for modifying, if necessary, only a few aspects during the compaction operations (Jang 1993; Guler, Ubeyli 2005; Mon 2007; Gu, Oyadiji 2008; Tahmasebi, Hezarkhani 2010).

\section{Method}

\subsection{Generality}

In the construction phase the executor attempts to achieve the degree of compaction required by the designer. However, there are no direct relationships or analytical procedures that allow to precisely determine the weight of the roller, the number of passes, the speed or the dynamic characteristics (frequency and amplitude) of the roller, the layer thickness, etc. As a matter of fact, it is not easy to define an in situ activity that brings to the material the same energy as in the laboratory (for example by gyratory compactor), because in reality there are many variables that make this a very complex phenomenon. The problem is usually solved by unloading some laying test, in which some variables, such as roller speed, number of passes, the vibration amplitude and frequency, length of paving, etc. will vary within appropriate limits. In the so compacted layer, a few cores have to be extracted and carried in laboratory for measuring the density. The best result will now give the general guidelines for a proper execution.

This approach, although very simple, involves some diseconomies. First of all, the laying test is unlikely to be definitive, since some areas have densities below the prescribed limit and, therefore, must be demolished. The second drawback concerns the time and cost required to execute the paving, to extract and test a number of cores within a certain time. The last negative aspect of this procedure is that the executor, on the basis of laboratory results, will set out certain factors in order to achieve the desired result, without understanding which of these is actually more important.

In order to overcome these problems the present paper proposes a procedure based on a reasonable survey of relevant data concerning the main variables and a subsequent analysis to identify those most influential at this regard.

Both the survey and the analysis are carried out almost in real time and provide rapid information to the operator, thus eliminating all the disadvantages of the traditional methodology before outlined. The proposed procedure, however, is very flexible: there are no constraints on the type of compacting equipment or work organization, nor on the size of the data set. At this stage of research, in order to verify the correctness of the methodology, the number of variables is quite small ( 9 input variables and 1 output) but the proposed technique is suitable to use a very large number of features and subsequently it increases the size of database. Among the parameters measured, the density will be measured by means of a non-nuclear instrument. In particular, an electrical density gauge, like TransTech's Pavement Quality Indicator (PQI), measures pavement compaction by means of its dielectric constant. The instrument introduces a weak current through the material, which creates an electrical sensing field. The output depends on the response of this electrical sensing field to changes in the pavement's complex impedance (consisting of the pavement's composite resistivity and dielectric constant). This response is then calibrated to pavement density.

The variables that were detected in situ during the execution of lying and feeding the database are as follows:

- Sp: Roller Speed in $\mathrm{km} / \mathrm{h}$;

- Th: Layer Thickness in $\mathrm{cm}$. Although the thickness is designed equal to $3 \mathrm{~cm}$, small deviations from this value have been measured;

- Ti: Time in seconds. It is relative to the elapsed time during the single pass and it is, therefore, a partial measure;

- Pr: Progressive in seconds. It takes into account the cumulative time during all the passes up to the time of the record and it is, therefore, a progressive measure;

- Pa: Passes number;

- Te_A: Air temperature in ${ }^{\circ} \mathrm{C}$;

- Wa: Water in \%. It is the water needed to avoid the pick up on the drum of the hot material;

- Te_M: Material temperature in ${ }^{\circ} \mathrm{C}$;

- De: Density of the compacted material in $\mathrm{kN} / \mathrm{m}^{3}$.

Other parameters, although detected, have been assumed constants because of their modest variability (for example roller weight) and will not be processed numerically in the later stages of the analysis.

As mentioned above, a soft computing technique for reducing the $\mathrm{N}$-dimensional data set initially collected will be applied. Generally, soft computing can be used to deal with a very wide range of problems, as classification, optimization, data mining, prediction, decision support, especially when:

- The system is non-linear, time-variant or ill defined;

- The variables are continuous;

- A mathematical model is either too difficult or expansive to organize;

- There are too many or noisy inputs;

- An expert is available to interpret the rules that should determine the system behaviour. 
The choice of the most correct technique depends on the type of problem and the available data. Neural Networks are good at classification, data-mining and prediction systems, where there are lots of potentially noisy input data available but they suffer from a lack of intelligibility, because of the computation is hidden in the weights and thresholds of multiply connected networks. Fuzzy Logic systems are best suited to decision making and control systems when the rules of the model cannot be translated to hard mathematical formulae. These rules are used to perform a logical, non-linear mapping between inputs and outputs, in the same way of human decision-making processes. In the recent past, some researchers (Jang 1993) have shown the convenience to pair the methods previously seen in order to maximize the benefits. For example, one of the most effective procedures, that is the neuro-fuzzy approach, consists of a structure that uses both fuzzy logic and neural networks. In detail, neural networks recognize patterns and help adaptation to the environment while fuzzy models incorporate a database, which defines the membership functions used in the rules by means of a preventive procedure of clustering, and a reasoning mechanism, which performs the inference procedure upon the rules. In a few words, this procedure takes a fuzzy model and adjusts it with a back propagation algorithm based on the collection of input-output data.

\subsection{Brief notes about neuro-fuzzy}

Neuro-fuzzy techniques exploit Artificial Neural Networks (ANNs) procedures to determine the properties of fuzzy sets and fuzzy rules by processing data sets. The most famous approach in this field is the adaptive neurofuzzy inference system (ANFIS), in which the membership function parameters and the rules are extracted from a data set opportunely surveyed (Jang 1993).

The model is trained with the back-propagation gradient descent method and because of slowness, it is combined with the least squares method.

To illustrate the methodology behind the procedure, we can introduce a simple example with two fuzzy if-then rules based on a first order Sugeno model (Fig. 1):

Rule 1:

$$
\text { If }\left(x \text { is } A_{1}\right) \text { and }\left(y \text { is } B_{1}\right) \text { then }\left(f_{1}=p_{1} x+q_{1} y+r_{1}\right) \text {; }
$$

Rule 2:

If $\left(x\right.$ is $\left.A_{2}\right)$ and $\left(y\right.$ is $\left.B_{2}\right)$ then $\left(f_{2}=p_{2} x+q_{2} y+r_{2}\right)$,

where $x$ and $y$ are the inputs; $A_{i}$ and $B_{i}$ are the fuzzy sets; $f_{i}$ are the outputs; $p_{i}, q_{i}$ and $r_{i}$ are the design parameters that are determined during the training progression. In the Figure 2 a circle indicates a fixed node and a square is an adaptive node.

With reference to the Figure 2, the first layer is composed by adaptive nodes and the outputs are the fuzzy membership grade of the inputs, given by:

$$
\begin{gathered}
O_{i}^{1}=\mu_{A i}(x) \text { with } i=1,2 ; \\
O_{i}^{1}=\mu_{B i-2}(y) \text { with } i=3,4 .
\end{gathered}
$$

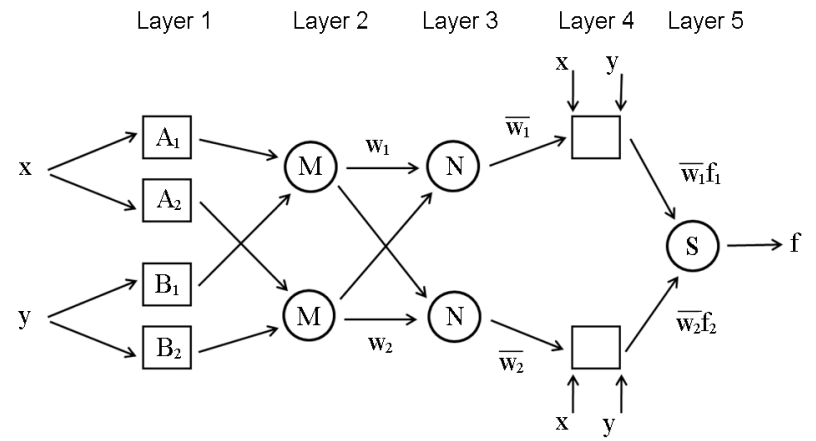

Fig. 1. ANFIS architecture

In the second layer, there are only fixed nodes and they are simple multiplier (M). The outputs can be expressed as:

$$
O_{i}^{2}=w_{i}=\mu_{A i}(x) \cdot \mu_{B i}(y) \text { with } i=1,2,
$$

called the firing strengths of the rules.

Also in the third layer, the nodes, labelled with $\mathrm{N}$, are all fixed. They normalize the firing strengths from the previous layer.

The outputs can be reported as:

$$
O_{i}^{3}=\bar{w}_{i}=\frac{w_{i}}{w_{1}+w_{2}} \quad \text { with } 1=1,2 .
$$

In the fourth layer, there are only adaptive nodes. The output is the product of the normalized firing strength and a first order polynomial:

$$
O_{i}^{4}=\bar{w}_{i} \cdot f_{i}=\bar{w}_{i} \cdot\left(p_{i} x+q_{i} y+r_{i}\right) \quad \text { with } 1=1,2 .
$$

In the fifth layer, there is a single fixed node (S) that sums all incoming signals:

$$
O_{i}^{5}=\sum_{i=1}^{2} \bar{w}_{i} \cdot f_{i}=\frac{\sum_{i=1}^{2} w_{i} \cdot f_{i}}{w_{1}+w_{2}} .
$$

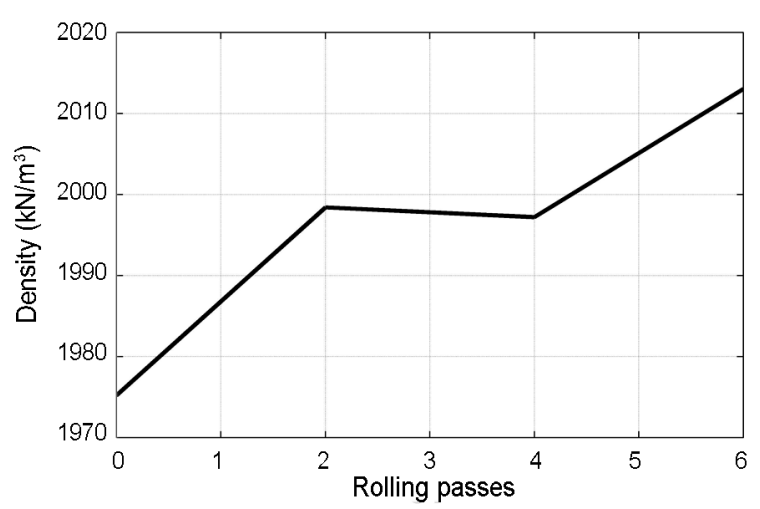

Fig. 2. Relationship between Rolling Passes and Density deduced by individual tests of compaction. The trend shows a subhorizontal line, due to the resistance of the material already partially compacted to the rolling action which will be won only after several passes (after four passes) 
In the first adaptive layer there could be three modifiable parameters called $a_{i}, b_{i}, c_{i}$, (premise parameters) related to the input membership functions. In the fourth adaptive layer, there are different modifiable parameters (called consequent parameters) $p_{i}, q_{i}, r_{i}$, pertaining to the first order polynomial. The learning algorithm is designed to calibrate all the modifiable parameters as $\left\{\mathrm{a}_{\mathrm{i}}, \mathrm{b}_{\mathrm{i}}, \mathrm{c}_{\mathrm{i}}\right\}$ and $\left\{p_{i}, q_{i}, r_{i}\right\}$, to make the output compatible with the training data.

When the membership functions are fixed, the output can be written as:

$$
f=\frac{w_{1}}{w_{1}+w_{2}} f_{1}+\frac{w_{2}}{w_{1}+w_{2}} f_{2} .
$$

And, finally:

$$
f=\bar{w}_{1} f_{1}+\bar{w}_{2} f_{2} .
$$

And substituting the fuzzy if-then rules into the last equation:

$$
f=\bar{w}_{1}\left(p_{1} x+q_{1} y+r_{1}\right)+\bar{w}_{2}\left(p_{2} x+q_{2} y+r_{2}\right) .
$$

In this way and after some rearrangement, the output can be expressed as:

$$
\begin{aligned}
f= & \left.\left(\bar{w}_{1} x\right) p_{1}+\left(\bar{w}_{1} y\right) q_{1}+\left(\bar{w}_{1}\right) r_{1}\right)+\left(\bar{w}_{2} x\right) p_{2}+ \\
& \left.\left(\bar{w}_{2} y\right) q_{2}+\left(\bar{w}_{2}\right) r_{2}\right) .
\end{aligned}
$$

As mentioned, a hybrid algorithm combining the least squares method and the gradient descent method can be used to identify in a faster way the optimal values of these parameters, especially when the premise parameters are not fixed.

In particular, when the premise parameters are fixed, the least squares method (forward pass) is used to optimize the consequent parameters. Once the optimal consequent parameters are found, the gradient descent method (backward pass) is used to adjust in an optimal mode the premise parameters corresponding to the fuzzy sets in the input domain. The output of the ANFIS is calculated by using the consequent parameters already found in the forward pass, while the output error permits to adapt the premise parameters with the backpropagation algorithm (Jang 1993).

\section{Results}

\subsection{Application}

The methodology described above has been applied to the lay down of a hot mix asphalt surface layer in a rural road located near the town of Messina (Italy). The cross section of the road has two lanes from $4 \mathrm{~m}$ each, of which the first one has been used by the workers and operative vehicles and in the other paving has taken place. The asphalt plant is near the construction site and this has allowed to the material to have temperatures high enough to ensure a reasonable useful period for compaction.

Paving occurred with a floating screed, for a width of $4.00 \mathrm{~m}$, a nominal thickness of the layer of $3 \mathrm{~cm}$ and a speed of $0.45 \mathrm{~km} / \mathrm{h}$. The floating screed has been immedi- ately followed by a roller with double metallic drum, weight of $11.300 \mathrm{kN}$, drum width of $1.950 \mathrm{~m}$, which has compacted the material in static mode with a speed of $2 \mathrm{~km} / \mathrm{h}$.

The measures have been recorded in 40 sections and the final number of passes has depended on the level of compaction achieved. When this result has been satisfactory or material temperature has been too low, the number of passes increased. In this way, a database consisting of 10 columns ( 9 input variables and one output), with 72 rows (observations), has been acquired. It is partially shown in Table 2.

In the following figures some results obtained in section no. 1 are presented. They are easily understandable and show the impossibility to derive from these relationships useful indications to perform the compaction in the best way.

As previously mentioned, the nine input variables are not all of equal significance in influencing compaction. Therefore, the purpose of the procedure was to identify the most important variables both individually and in groups.

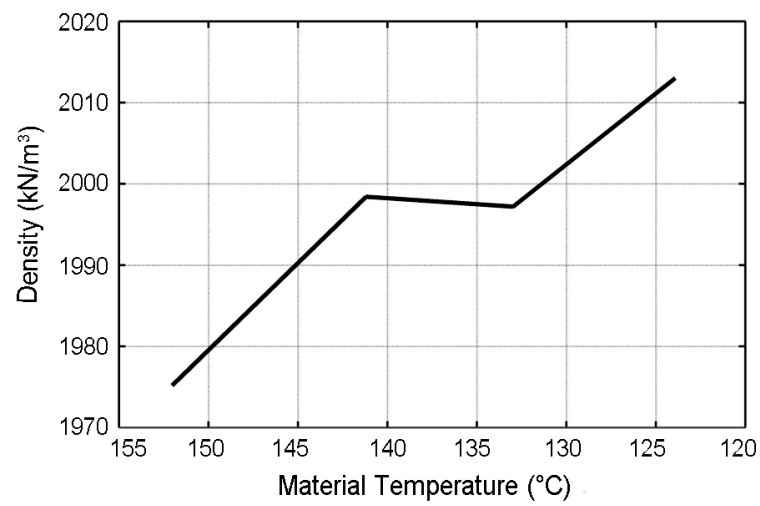

Fig. 3. Relationship between Material Temperature and Density deduced by individual tests of compaction. The high temperature of the hot mix allows further compaction of the material even after numerous passes

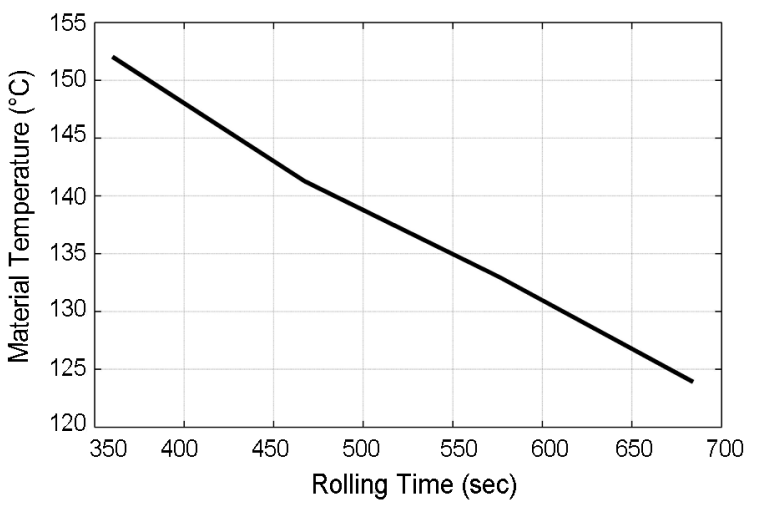

Fig. 4. Relationship between Material Temperature and Rolling Time deduced by individual tests of compaction. It can be assumed that 700 seconds (about 11 minutes) is the maximum time beyond which there is no more an effective compaction of the material. Beyond this time, in fact, only the aesthetic appearance of the pavement surface can improve 
Table 2. Data set of the survey

\begin{tabular}{ccccccccccc}
\hline & Sp & Le & Th & Ti & Pr & Pa & Te_A & Wa & Te_M & $\gamma$ \\
\hline 1 & 0.6 & 60 & 3.1 & 360 & 360 & 0 & 28 & 4.88 & 152 & 1975 \\
\hline 2 & 2.0 & 60 & 3.0 & 108 & 468 & 2 & 28 & 5.32 & 141 & 1998 \\
\hline 3 & 2.0 & 60 & 3.2 & 108 & 576 & 4 & 28 & 4.96 & 133 & 1997 \\
\hline 4 & 2.0 & 60 & 3.0 & 108 & 684 & 6 & 28 & 5.12 & 124 & 2013 \\
\hline 5 & 0.6 & 50 & 3.0 & 300 & 300 & 0 & 28 & 5.38 & 123 & 1971 \\
\hline 6 & 2.0 & 50 & 3.2 & 90 & 390 & 2 & 28 & 5.50 & 109 & 2003 \\
\hline $\mathrm{n}$ & $\ldots$ & $\ldots$ & $\ldots$ & $\ldots$ & $\ldots$ & $\ldots$ & $\ldots$ & $\ldots$ & $\ldots$ & $\ldots$ \\
\hline
\end{tabular}

In brief, the procedure can be summarized in the following steps:

- Collection of a training data set (the first 300 observations) that contains the desired input/output data of the system to be modelled;

- Specification of an initial model structure (in this case, it was the Sugeno type);

- After generating the initial fuzzy model structure, training by means of back-propagation form of the steepest descent method. The optimization method train the membership function parameters to emulate the training data;

- After the fuzzy model is trained, validation using a testing or checking data different from the used one;

- In the present case, a part of the observations (300) were used to select the best classifier (respectively, with one, with a pair and with three variables at a time) and the remainder (60) to estimate the error rate of trained classifier.

The steepest descent method is a first-order optimization algorithm. To find a local minimum of a function this procedure takes steps proportional to the negative of the function gradient at the current point. On the contrary, if the steps are proportional to the positive of the gradient, a local maximum of that function will be approached. The training error is the difference between the training data output value and the output of the fuzzy system corresponding to the same training data input value (the one associated with that training data output value). The training error records the Root Mean Squared Error (RMSE) of the training data set. The checking error is the difference between the checking data output value and the output of the fuzzy system corresponding to the same checking data input value, which is the one associated with that checking data output value. The Root Mean Squared Error (RMSE) has measured the average mismatch between each data point and the model and therefore it has provided an answer about the correctness of the procedure. As it is known, if the value of RMSE is zero, the model has performed in a perfect way the survey data and, on the contrary, high RMSE results can indicate a bad fit. The least error indicates the most influent feature but it is also important to verify the difference between training and checking errors because a high value would indicate the presence of overfitting.

The results from the previous simulations (Tables 3-5) show that, at least from the numerical point of
Table 3. Evaluation of the most influent feature by means of ANFIS and quantification of RMSE

\begin{tabular}{cccc}
\hline Input & Training & Checking & Difference \\
\hline $\mathrm{Ti}$ & 0.0995 & 0.0812 & 0.0183 \\
$\mathrm{~Pa}$ & 0.1029 & 0.0858 & 0.0171 \\
$\mathrm{Sp}$ & 0.1083 & 0.0962 & 0.0121 \\
$\mathrm{Pr}$ & 0.1114 & 0.1153 & 0.0039 \\
$\mathrm{Pe} \mathrm{M}$ & 0.1141 & 0.1201 & 0.006 \\
$\mathrm{Wa}$ & 0.1296 & 0.1633 & 0.0337 \\
$\mathrm{We}$ & 0.1322 & 0.1654 & 0.0332 \\
$\mathrm{Te}$ & 0.1375 & 0.1633 & 0.0258 \\
\hline $\mathrm{Te} A \mathrm{~A}$ & 0.1375 & 0.1657 & 0.0282 \\
\hline $\mathrm{Th}$ & & &
\end{tabular}

Table 4. Evaluation of two out of nine by means of ANFIS. The most influent features are the pair Time and Water and, in order to error differences, without problem of overfitting

\begin{tabular}{cccc}
\hline Input & Training & Checking & Difference \\
\hline Ti-Wa & 0.0682 & 0.077 & 0.0088 \\
Ti-Te_A & 0.0838 & 0.0726 & 0.0112 \\
Ti-Le & 0.0862 & 0.1065 & 0.0203 \\
\hline Ti-Th & 0.0916 & 0.0863 & 0.0053 \\
Ti-Pr & 0.0929 & 0.068 & 0.0249 \\
Ti-Pa & 0.0938 & 0.1159 & 0.0221 \\
Ti-Te_M & 0.0954 & 0.0967 & 0.0013 \\
Ti-Sp & 0.0989 & 0.0805 & 0.0184 \\
\hline
\end{tabular}

Table 5. Evaluation of three out of nine by means of ANFIS. The most influent features are the group Time, Water and Material Temperature and, in order to error differences, without problem of overfitting

\begin{tabular}{cccc}
\hline Input & Training & Checking & Difference \\
\hline Ti-Wa-Te_M & 0.0593 & 0.1053 & 0.046 \\
Ti-Wa-Pr & 0.0597 & 0.0918 & 0.0321 \\
Ti-Wa-Pa & 0.0598 & 0.1293 & 0.0695 \\
Ti-Wa-Te_A & 0.0598 & 0.1777 & 0.1179 \\
Ti-Wa-Th & 0.0623 & 0.1192 & 0.0569 \\
\hline Ti-Wa-Le & 0.0641 & 0.083 & 0.0189 \\
Ti-Wa-Sp & 0.0673 & 0.084 & 0.0167 \\
\hline
\end{tabular}

view, Rolling Time (Ti) is the most influent feature. The analysis carried out with set of two and three variables at the same time has highlighted the role of, respectively, Rolling Time (Ti)-Water (Wa) and Rolling Time (Ti)Water (Wa)-Material Temperature (Te_M). The results drawn from the different simulations are fully consistent, as the most influential variables of the previous phase are confirmed later.

\section{Discussion}

Figures 2, 3 and 4 represent the trend of some features (density, rolling time, number of passes, etc.) deduced by individual test of compaction, regarding the section 1 and, therefore, they are indicative only of a small part of 
the experiment. However, their inclusion in this paper is necessary to understand the limits of this information. That is, the knowledge of a simple relationship between two variables is of little utility for the executor and does not provide any help in making decisions or for long-term strategy. On the contrary, it is necessary to organize an analytical, though simple, tool making it possible to take into account the influence of the variables that are present in the environment, not just those strictly related to the roller compactor or material characteristics.

As mentioned in Method section, a neuro-fuzzy technique has been applied. This approach assures quickness, especially with large data base even though the results may relate to local optima rather than global optimum. The examination of numerical results shows some interesting aspects. First, the analysis performed on a single variable makes little sense and only serves to classify the inputs in order of importance. At this regard, Table 3 shows that the compaction time (Ti) has the greatest relevance to the output. The training and checking errors are very close and this clearly indicates the absence of overfitting. The very similar values of the other variables show a strong dependence among them, as it is easy to understand.

The following table (Table 4) is certainly more interesting. As a matter of fact, it confirms the importance of $\mathrm{Ti}$, but also involves the $\mathrm{Wa}$, that is the percentage of water present during the rolling and released from the drum to avoid the adhesion with the asphalt mix. This is an aspect that would be escaped in a very complex rheological model, too. From the numerical point of view, the pair Ti-Wa is certainly the best choice even if others could give good results in terms of error and this is due to the inter-dependence of variables. The difference between the errors of training and checking is always negligible.

The last table (Table 5) identifies the group Ti-WaTe_M as the best selection among the triplets that affect the density. In fact, it is understandable the identification of the material temperature ( $\mathrm{Te} \_\mathrm{M}$ ) because this directly affects the compaction but also the time available for rolling. Errors in training this time indicate that this group has stronger influence on the output than any other triplet and also in this case we have a good response about the danger of overfitting.

This problem would have been presented if, for a given size of the matrix, we had increased the number of input variables or had grouped together four or more input features. This does not mean that these limits cannot be exceeded, but only that the data set have to grow in size.

The tables included in this article (Tables 3-5) need a last consideration. The input variables have error values still acceptable and, therefore, one could argue that this technique does not perform a sharp selection. Instead the tables show the best combinations in terms of training and checking error compared to the total. For example, the case of two variables simultaneously compared to the nine input, should produce a number of combinations of 36 pairs, while the case of three variables should produce 84 different combinations. It is obvious that the technique has allowed us to identify the best combinations and only these were reported in the tables.

\section{Conclusions}

With this research the authors have proposed a procedure that allows the rapid recognition of some variables that influence the process of compaction. As a matter of fact, although this aspect is generally studied with attention during the design phase, there are some factors that are characterized by uncertainty and variability and that severely affect the material density. For example, the rolling time is related to the temperature of the material that in turn depends on the distance from the asphalt plant and from the air temperature. Because of these uncertainties, traditional procedures require laying tests, characterized by different conditions, from which some cores will be extracted and sent to the laboratory. The test on cores provides a measure of the correctness of the methodology followed. However, these activities are carried out in a couple of days and if the boundary conditions change (air temperature and material, paving surfaces, humidity, etc.) it can be possible that the expected results are different from real measures.

For these reasons, the authors used an instrument that detects in real time the density of the material but have also applied some neuro-fuzzy techniques for sorting the data set collected and identifying the most important features in relation to density. This information allows to pay attention to those features so that to obtain the results required by the design. This will prevent the laying tests that, in the sections where the desired density do not achieve a minimal value, must be demolished. Again, there is a greater economy because it is no longer necessary to use laboratory tests with the same frequency. But, above all, it is possible to recognize, for that specific scenario, the most sensitive features.

The correctness of the proposed approach, even in relation to the existing literature, appears for certain aspects. The purely theoretical control of the phenomenon is, in our opinion, very complex. The transfer of compaction energy used in the laboratory, for example with the gyratory compactor, on site is difficult because the variables involved are a large number. Some of these are related to the roller and have static and dynamic characteristics; but other, more complex to control, are linked to the environment and are continuously modified. For this reason we need a procedure, perhaps less refined from the analytical point of view respect to the complex rheological models already existing in literature, but that would provide realistic answers and in a very short time.

\section{References}

Airey, G. D.; Hunter, A. E.; Collop A. C. 2008. The effect of asphalt mixture gradation; compaction energy on aggregate degradation, Construction and Building Materials 22(5): 972-980.

http://dx.doi.org/10.1016/j.conbuildmat.2006.11.022

Altunok, E.; Reda Taha, M. M.; Epp, D. S.; Mayes, R. L.; Baca, T. J. 2006. Damage pattern recognition for structural health monitoring using fuzzy similarity prescription, 
Computer-Aided Civil and Infrastructure Engineering 21(8): 549-560. http://dx.doi.org/10.1111/j.1467-8667.2006.00457.x

Bell, C. A.; Hicks, R. G.; Wilson, J. E. 1984. Effect of percent compaction on asphalt mixture life, in Wagner, F. T. (Ed.). Placement and Compaction of Asphalt Mixtures, ASTM Special Technical Publication 829. American Society for Testing and Materials, Philadelphia, PA, 107-130. http://dx.doi.org/10.1520/STP32504S

Bosurgi, G.; D'Andrea, A.; Pellegrino, O. 2010. Could drivers' visual behaviour influence road design?, Advances in Transportation Studies 22: 17-30.

Bosurgi, G.; D'Andrea, A.; Pellegrino, O. 2011. Context sensitive solutions using interval analysis, Transport 26(2): 171-177. http://dx.doi.org/10.3846/16484142.2011.589425

Brown, E. R. 1984. Experiences of corps of engineers in compaction of hot asphalt mixtures, in Wagner, F. T. (Ed.). Placement and Compaction of Asphalt Mixtures, ASTM Special Technical Publication 829. American Society for Testing and Materials, Philadelphia, PA, 67-79. http://dx.doi.org/10.1520/STP32501S

Chao, L. C. 2007. Fuzzy logic model for determining minimum bid markup, Computer-Aided Civil and Infrastructure Engineering 22(6): 449-460. http://dx.doi.org/10.1111/j.1467-8667.2007.00500.x

Chiu, S. L. 1996. Selecting input variables for fuzzy models, Journal of Intelligent and Fuzzy Systems 4(4): 243-256.

Commuri, S.; Zaman, M. 2008. A novel neural network-based asphalt compaction analyzer, International Journal of Pavement Engineering 9(3): 177-188. http://dx.doi.org/10.1080/10298430701232018

Dagdeviren, M.; Yuksel, I.; Kurt, M. 2008. A fuzzy analytic network process (ANP) model to identify faulty behaviour risk (FBR) in work system, Safety Science 46(5): 771783. http://dx.doi.org/10.1016/j.ssci.2007.02.002

Dorsey, D. W.; Coovert, M. D. 2003. Mathematical modeling of decision making: a soft and fuzzy approach to capturing hard decisions, Human Factors 45(1): 117-135. http://dx.doi.org/10.1518/hfes.45.1.117.27228

Dubois, D.; Prade, H. 1998. An introduction to fuzzy systems, Clinica Chimica Acta 270(1): 3-29. http://dx.doi.org/10.1016/S0009-8981(97)00232-5

Dubois, V.; De La Roche, C.; Burban, O. 2010. Influence of the compaction process on the air void homogeneity of asphalt mixtures samples, Construction and Building Materials 24(6): 885-897.

http://dx.doi.org/10.1016/j.conbuildmat.2009.12.004

Duda, R. O.; Hart, P. E.; Stork, D. G. 2001. Pattern classification. $2^{\text {nd }}$ ed. John Wiley and Sons, USA. 680 p.

Geller, M. 1984. Compaction equipment for asphalt mixtures, in Wagner, F. T. (Ed.). Placement and Compaction of Asphalt Mixtures, ASTM Special Technical Publication 829. American Society for Testing and Materials, Philadelphia, PA, 28-47. http://dx.doi.org/10.1520/STP32499S

Grassi, A.; Gamberini, R.; Mora, C.; Rimini, B. 2009. A fuzzy multi-attribute model for risk evaluation in workplaces, Safety Science 47(5): 707-716. http://dx.doi.org/10.1016/j.ssci.2008.10.002

Gu, Z. Q.; Oyadiji, S. O. 2008. Application of MR damper in structural control using ANFIS method, Computers and Structures 86(3-5): 427-436. http://dx.doi.org/10.1016/j.compstruc.2007.02.024
Guler, I.; Ubeyli, E. D. 2005. Adaptive neuro-fuzzy inference system for classification of EEG signals using wavelet coefficients, Journal of Neuroscience Methods 148(2): 113121. http://dx.doi.org/10.1016/j.jneumeth.2005.04.013

Hildebrand, R.; Keskinen, E.; Romero Navarrete, J. A. 2008. Vehicle vibrating on a soft compacting soil half-space: ground vibrations, terrain damage, and vehicle vibrations, Journal of Terramechanics 45(4): 121-136. http://dx.doi.org/10.1016/j.jterra.2008.09.003

Hughes, C. S. 1989. National cooperative highway research program synthesis of highway practice 152, Compaction of Asphalt Pavement. Washington, D.C.: Transportation Research Board National Research Council.

Jang, J. S. R. 1993. ANFIS: adaptive-network-based fuzzy inference systems, IEEE Trans, Systems, Man, and Cybernetics 23(3): 665-685. http://dx.doi.org/10.1109/21.256541

Jordan, P. G.; Thomas, M. E. 1976. Prediction of cooling curves for hot-mix paving materials by a computer program, Final Report No. 729, Transport and Road Research Laboratory, UK.

Kavussi, A.; Hashemian, L. 2011. Properties of WMA - foam mixes based on major mechanical tests, Journal of Civil Engineering and Management 17(2): 207-216. http://dx.doi.org/10.3846/13923730.2011.576825

Khan, Z. A.; Al-Abdul Wahab, H. I.; Asi, I.; Ramadhan, R. 1998. Comparative study of asphalt concrete laboratory compaction methods to simulate field compaction, Construction and Building Materials 12(6-7): 373-384. http://dx.doi.org/10.1016/S0950-0618(98)00015-4

Koneru, S.; Masad, E.; Rajagopal, K. R. 2008. A thermomechanical framework for modeling the compaction of asphalt mixes, Mechanics of Materials 40(10): 846-864. http://dx.doi.org/10.1016/j.mechmat.2008.03.008

Krishnamurthy, B. K.; Tserng, H. P.; Schmitt, R. L.; Russell, J. S.; Bahia, H. U.; Hanna, A. S. 1998. Autopave: towards an automated paving system for asphalt pavement compaction operations, Automation in Construction 8(2): $165-180$. http://dx.doi.org/10.1016/S0926-5805(98)00060-0

Leng, Z.; Al-Qadi, I. L.; Lahouar, S. 2011. Development and validation for in situ asphalt mixture density prediction models, NDT and E International 44(4): 369-375. http://dx.doi.org/10.1016/j.ndteint.2011.03.002

McLachlan, G. J. 2004. Discriminant analysis and statistical pattern recognition. Wiley - IEEE.

Mon, Y. J. 2007. Airbag controller designed by adaptivenetwork-based fuzzy inference system (ANFIS), Fuzzy Sets and Systems 158(24): 2706-2714. http://dx.doi.org/10.1016/j.fss.2007.06.005

Papoulis, A.; Pillai, S. U. 2002. Probability, random variables and stochastic processes. McGraw-Hill.

Pellegrino, O. 2011. Road context evaluated by means of fuzzy interval, Cognition, Technology and Work 13(1): 67-79. http://dx.doi.org/10.1007/s10111-010-0155-2

Pellegrino, O. 2012. The application of drivers' cognitive reliability using fuzzy techniques, Applied Artificial Intelligence 26(6): 517-540. http://dx.doi.org/10.1080/08839514.2012.670973

Praticò, F. G.; Moro, A. 2011. In-lab and on-site measurements of hot mix asphalt density: convergence and divergence hypotheses, Construction and Building Materials 25(2): 1065-1071. http://dx.doi.org/10.1016/j.conbuildmat.2010.06.071 
Reuter, U.; Moller, B. 2010. Artificial neural networks for forecasting of fuzzy time series, Computer-Aided Civil and Infrastructure Engineering 25(5): 363-374. $\mathrm{http}: / / \mathrm{dx}$.doi.org/10.1111/j.1467-8667.2009.00646.x

Ripley, B. D. 2005. Pattern recognition and neural networks. $8^{\text {th }}$ ed. Cambridge: Cambridge University Press.

Roberts, F. L.; Kandhal, P. S.; Brown, R. E.; Lee, D. Y.; Kennedy, T. W. 1996. Hot mix asphalt materials, mixture design, and construction. $2^{\text {nd }}$ ed. NAPA Education Foundation, Lanham Maryland.

Sadeghi, N.; Fayek, A. R.; Pedrycz, W. 2010. Fuzzy Monte Carlo simulation and risk assessment in construction, Computer-Aided Civil and Infrastructure Engineering 25(4): 238-252. http://dx.doi.org/10.1111/j.1467-8667.2009.00632.x

Schercman, J. A. 1984. Guidelines for compacting asphalt concrete pavement, Better Roads 54: 12-17.

Scherocman, J. A.; Martenson, E. D. 1984. Placement of asphalt concrete mixtures, in Wagner, F. T. (Ed.). Placement and
Compaction of Asphalt Mixtures, ASTM Special Technical Publication 829. American Society for Testing and Materials, Philadelphia, PA, 3-27. http://dx.doi.org/10.1520/STP32498S

Tahmasebi, P.; Hezarkhani, A. 2010. Application of adaptive neuro-fuzzy inference system for grade estimation, Australian Journal of Basic and Applied Sciences 4(3): 408420.

Theodoridis, S.; Koutroumbas, K. 2006. Pattern recognition. $3^{\text {rd }}$ ed. USA: Academic Press.

Transportation Research Board. 2006. Factors affecting compaction of asphalt pavements - General issues in asphalt technology committee. Transportation Research Circular E-C105. Washington, D.C.

Webb, A. R. 2002. Statistical pattern recognition. $2^{\text {nd }}$ ed. John Wiley and Sons Ltd. 496 p. http://dx.doi.org/10.1002/0470854774

Antonio AMADORE. PhD, a road engineer and an expert of Road Construction at University of Messina, Italy. He is a member of the Società Italiana Infrastrutture Viarie (SIIV) and PIARC (World Road Association). His research interests include the behaviour of road materials, with a particular penchant for recycled ones.

Gaetano BOSURGI. An Associate Professor in the Department of Civil Engineering at the University of Messina and, actually, is also the President of the Degree Course. He is a member of the Società Italiana Infrastrutture Viarie (SIIV), of the Permanent International Association of Road Congresses (PIARC) - National Technical Committee C4-2 and of the Associazione Nazionale Italiana di Ingegneria Sismica (ANIDIS). His research interests include the study of road pavements, materials, safety, management and driver's behaviour, published in about ninety papers with National and International relevance.

Orazio PELLEGRINO. PhD, a lecturer at the Department of Civil Engineering at the University of Messina. He is a member of the Società Italiana Infrastrutture Viarie (SIIV) and of the Human Factors and Ergonomics Society (HFES). His research interests include the study of road materials, safety and driver's behaviour. 